\title{
DIVERSIDADE LINGUÍSTICA EM LIVRO DIDÁTICO DE PORTUGUÊS: ALGUNS APONTAMENTOS
}

\author{
Paula Gaida Winch
}

\begin{abstract}
RESUMO
Analisa-se como a diversidade linguística é tratada em livro didático de português, no qual dois capítulos se destinam a ela. Neles, salienta-se que a origem étnica do falante pode manifestar-se diferentemente por: alteraçóes morfológicas; uso de expressóes estrangeiras; sotaque. Em suma, a diversidade linguística é tratada mediante atividades de identificação e de reprodução de variedades linguísticas a serem realizadas pelos alunos.
\end{abstract}

PALAVRAS-CHAVE: diversidade linguística; ensino; língua portuguesa.

\section{Homogeneidade e diversidade linguísticas}

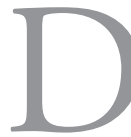

urante os séculos XVI ao XIX, percebemos a predominância de uma política linguística, cujo foco era tratar a língua portuguesa (doravante LP) como uma unidade homogênea, ou seja, como sendo a língua falada por todos os brasileiros, de norte a sul, e da mesma forma. Assim, não se reconhecia que a língua falada poderia apresentar diferenças de uma comunidade para outra, em razão do espaço geográfico em que o sujeito se encontra, de sua faixa etária, de sua posição social, de sua condição financeira, de sua origem étnica, especialmente, em relação aos imigrantes (africanos, holandeses, entre outros) e aos indígenas aqui residentes. Contudo, esses dois últimos grupos de indivíduos - imigrantes e indígenas - não tinham a LP como língua materna. 
Mariani ${ }^{1}$ explica que a construção desse imaginário da LP como homogênea "assegurou a Portugal sua unidade e identidade como nação, de forma a garantir na colônia a reprodução desse imaginário”. Observamos, nessa afirmação, que a ideia de língua homogênea esteve associada, ou melhor, a serviço da construção de uma identidade nacional. Essa associação entre língua e identidade nacional surgiu primeiramente em Portugal e, após, foi trazida ao Brasil, tornando-se mais explícita mediante a Reforma Pombalina, que tornou obrigatório o uso e o ensino da LP, no Brasil, como forma de desenvolver uma identificação no país colonizado.

Para construir essa identidade nacional do Brasil, a partir da língua utilizada por seus falantes, ou seja, reproduzir o imaginário de uma língua homogênea, ocorreu um processo de silenciamento, de apagamento das línguas indígenas e das línguas trazidas pelos imigrantes que aqui se inseriram ${ }^{2}$.

O silenciamento ou apagamento de línguas distintas da LP provoca um efeito de coincidência entre a língua nacional, a língua portuguesa e a língua materna. Pfeiffer ${ }^{3}$ expóe, claramente, como a língua nacional confunde-se com a língua materna e parecem ser ambas representadas na LP: "Na ordem do imaginário, espaço da organização dos sentidos, tudo se passa como se o sujeito de linguagem brasileiro fosse à escola para aprender a sua língua materna e não a língua nacional, ambas retomadas na opacidade da designação 'língua portuguesa”".

$\mathrm{O}$ efeito de coincidência entre essas línguas causa a impressão de que todos sempre falaram LP e que a falam da mesma forma, sem diferenças na pronúncia, na construção sintática e no léxico. No âmbito dessa política linguística que preza pelo purismo - língua pura -, não há espaço para contemplar a diversidade linguística dos falantes residentes no Brasil, durante período colonial e imperial.

Para consolidar a língua pura, alguns artefatos, vistos como instrumentos linguísticos, foram criados tais como a gramática e o dicionário, com a função

MARIANI, Bethania. Colonização linguística. Campinas: Pontes, 2004, p. 31.

2 PAYER, M. Onice. "Processos de identificação sujeito/língua: Ensino, Língua Nacional e Língua Materna”. In: ORLANDI, Eni P. (Org.) Politica linguistica no Brasil. Campinas: Pontes, 2007. p. 113-123.

3 PFEIFFER, Claúdia. "Instrumentos linguísticos, ensino e políticas públicas: uma relação na história das ideias linguísticas”. In: VALENTE, André C.; PEREIRA, Maria T. G. (Orgs.) Lingua portuguesa: descrição e ensino. São Paulo: Parábola, 2011. p. 95-106, p. 99 
de fixar as regras de uso da linguagem, bem como os vocábulos pertencentes à língua. Desenvolvendo-se um ensino da língua com base nesses instrumentos, ter-se-ia garantida a homogeneidade linguística entre os falantes pertencentes a uma mesma nação.

Essa situação de homogeneidade linguística começa a mudar no espaço escolar a partir da década de 70, quando há uma inserção mais efetiva da linguagem utilizada nos meios de comunicação. Na referida década, os meios de comunicação começam a fazer uso de uma linguagem mais próxima da "linguagem popular", inserindo variantes linguísticas, com o intuito de tornar mais eficiente sua comunicação com o povo ${ }^{4}$.

Há também, no mesmo período, uma mudança no alunado que frequenta o espaço escolar, conforme ressalta Geraldi ${ }^{5}$. Segundo o autor, a questão de o professor ter de se preocupar com o tratamento didático a ser dado às variedades da língua, apresentadas no falar de seus alunos, passou a ser discutida após o processo de democratização da escola, quando houve inserção de alunos oriundos de classes de menor prestígio social e os quais apresentavam diferenças bem pontuadas na linguagem que utilizavam.

Começa-se a vivenciar, assim, um período de transição entre a homogeneidade e a heterogeneidade linguística, reconhecendo-se que a diversidade linguística é parte constitutiva da LP, de modo que essa diversidade não é mais tratada como fator negativo para a manutenção da unidade de uma língua; mas sim, como fator constitutivo dessa unidade.

Em decorrência dessas sinalizaçóes de mudança na forma de conceber a diversidade linguística, inicia-se uma reflexão sobre como ela pode ser tratada no espaço escolar, enfatizando-se a relação que se poderia ou deveria estabelecer entre o ensino da língua tida como culta e a consideração das variantes linguísticas apresentadas pelos alunos.

Vale mencionarmos aqui alguns linguistas, ou melhor, sociolinguistas, e seus posicionamentos em relação ao ensino de LP, considerando as variantes dessa língua.

4 PRETI, Dino. "O ensino de Língua Portuguesa: na encruzilhada entre a escrita e a oralidade”. In: BASTOS, N. B. Lingua Portuguesa: História, Perspectivas, Ensino. Sáo Paulo: EDUC, 1998. p. 85-93.

5 GERALDI, João Wanderley. “Concepçôes de linguagem e ensino de Português”. In: (Org.). In: O texto na sala de aula. 2. ed. Cascavel: ASSOESTE, 1984, p. 41-48. 
Preti ${ }^{6}$, traçando um paralelo entre transformaçóes linguísticas e as sociais, relata que os estudos sociolinguísticos, em especial a partir de suas ideias de variação linguística, vieram sinalizar que a avaliação da língua não poderia mais se basear no binômio certo/errado, tendo como parâmetro a gramática tradicional. Devia-se analisar a língua como adequada ou inadequada em função da situação comunicativa em que ela é utilizada, adotando como referencial, nessa avaliação, aspectos como:

prestígio social da linguagem; associação entre variantes e poder político-social; ligação entre língua e poder social dos falantes; entre variantes linguísticas e fatores externos como sexo, faixa etária, profissão e status, grau de escolaridade, e nível cultural dos interlocutores; mudanças de situação de comunicação e variação de registros, etc... ${ }^{7}$

Outra ideia proveniente da sociolinguística, também mencionada pelo referido autor, é o reconhecimento de que um mesmo falante assume diferentes papéis sociais durante convívio em sociedade e tem necessidades comunicativas distintas, o que repercute em variaçóes na linguagem utilizada por ele. Diante disso, Preti expóe que "um falante culto deveria ter o domínio de todas as variantes para adequá-las às situaçôes de comunicação"

Magda Soares" aponta duas posiçóes divergentes quanto ao tratamento a ser dado às variantes linguísticas no espaço escolar: a) a variedade linguística das classes populares deveria ser respeitada e preservada, sendo assumida no

6 PRETI, Dino. "O ensino de Língua Portuguesa: na encruzilhada entre a escrita e a oralidade". In: BASTOS, N. B. Lingua Portuguesa: História, Perspectivas, Ensino. São Paulo: EDUC, 1998. p. 85-93.

7 PRETI, Dino. "O ensino de Língua Portuguesa: na encruzilhada entre a escrita e a oralidade”. In: BASTOS, N. B. Lingua Portuguesa: História, Perspectivas, Ensino. São Paulo: EDUC, 1998. p. 85-93., p. 85-86.

8 PRETI, Dino. "O ensino de Língua Portuguesa: na encruzilhada entre a escrita e a oralidade". In: BASTOS, N. B. Lingua Portuguesa: História, Perspectivas, Ensino. Sáo Paulo: EDUC, 1998. p. 85-93, p. 86.

9 1983, apud GERALDI, João Wanderley. "Concepções de linguagem e ensino de Português". In: (Org.). In: O texto na sala de aula. 2. ed. Cascavel: ASSOESTE, 1984, p. 41-48. 
âmbito do discurso escolar; b) a variedade socialmente privilegiada deveria ser aprendida pelas classes populares como forma de superar, assim, as desigualdades sociais.

Geraldi ${ }^{10}$ apresenta um ponto de vista próximo à segunda posição, mencionando que "as atividades de ensino deveriam oportunizar aos seus alunos o domínio de uma outra forma de falar, o dialeto padrão, sem que isto signifique a depreciação da forma de falar predominante em sua família, em seu grupo social, etc.".

Quanto ao tratamento a ser atribuído às variedades linguísticas nos PCN-LP, salienta-se a necessidade de se reconhecer que nosso país apresenta uma unidade linguística - LP - que é constituída por muitas variedades, sendo que "o uso de uma ou outra forma de expressão depende, sobretudo, de fatores geográficos, sócio-econômicos, de faixa etária, de gênero (sexo), da relação estabelecida entre os falantes e do contexto de fala." ${ }^{11}$.

É necessário que essas variedades não sejam vistas e tratadas como erros, desvios ou incorreçôes por não seguirem a língua padrăo ou por não coincidirem com a modalidade escrita da língua. Ainda em consonância com o exposto nos PCN-LP, o estudo sistemático desse aspecto deve fazer parte das aulas de LP, já que

o que se almeja não é levar os alunos a falar certo, mas permitirlhes a escolha da forma de fala a utilizar, considerando as características e condiçóes do contexto de produção, ou seja, é saber adequar os recursos expressivos, a variedade de língua e o estilo às diferentes situaçóes comunicativas: saber coordenar satisfatoriamente o que fala ou escreve e como fazêlo; saber que modo de expressão é pertinente em função de sua intenção enunciativa, dado o contexto e os interlocutores a quem o texto se dirige. A questão não é de erro, mas de

10 GERALDI, João Wanderley. "Concepçôes de linguagem e ensino de Português". In: (Org.). In: O texto na sala de aula. 2. ed. Cascavel: ASSOESTE, 1984, p. 41-48, p. 45-46, grifo do autor.

11 BRASIL. Parâmetros curriculares nacionais: terceiro e quarto ciclos do ensino fundamental: Língua Portuguesa. Brasília: MEC/SEF, 1998, http://portal.mec.gov.br/seb/arquivos/pdf/ portugues.pdf, 12/01/2011, p. 29. 
adequação às circunstâncias de uso, de utilização adequada da linguagem. ${ }^{12}$

Para tanto, o documento traz propostas de atividades para abordar esse aspecto. Citamos aqui algumas delas: a) análise da força expressiva da linguagem popular na comunicação cotidiana, na mídia e nas artes, analisando depoimentos, filmes, peças de teatro, novelas televisivas, música popular, romances e poemas; b) levantamento das marcas de variação linguística ligadas a gênero, geraçóes, grupos profissionais, classe social e área de conhecimento, por meio da comparação de textos que tratem de um mesmo assunto para públicos com características diferentes; c) análise e discussão de textos de publicidade ou de imprensa que veiculem qualquer tipo de preconceito linguístico; d) análise comparativa entre registro da fala ou de escrita e os preceitos normativos estabelecidos pela gramática tradicional ${ }^{13}$.

Também encontramos preocupação explícita quanto ao tratamento das variantes linguísticas no ensino de LP, no Guia de livros didáticos PNLD ${ }^{14}$ 2011 ${ }^{15}$ : Língua Portuguesa ${ }^{16}$, no qual constam: a) critérios comuns e outros específicos por componente curricular, nesse caso LP, utilizados para avaliação e seleção das coleçooes didáticas ${ }^{17}$ a serem adotadas do $6^{\circ}$ ao $9^{\circ}$ ano do ensino fundamental; b) roteiros para análise dessas coleçóes por parte do corpo docente das escolas públicas de educação básica; c) fichas de análise das coleções; e, d) resenhas das respectivas coleções.

No documento em questão, consta, junto aos critérios específicos a que deve atender o livro didático de português (LDP), que o ensino de LP

12 BRASIL. Parâmetros curriculares nacionais: terceiro e quarto ciclos do ensino fundamental: Língua Portuguesa. Brasília: MEC/SEF, 1998, http://portal.mec.gov.br/seb/arquivos/pdf/ portugues.pdf, 12/01/2011, p. 31 .

13 Ibid., p. 82-83.

14 PNLD refere-se ao Programa Nacional do Livro Didático.

15 O Guia de Livros Didáticos - PNLD 2011 será referenciado como “Guia 2011”.

16 BRASIL. Guia de livros didáticos - PNLD 2011: Língua Portuguesa. Brasília: MEC/ SEB, 2010, http://www.fnde.gov.br/index.php/pnld-guia-do-livro-didatico/2349-guia-pnld-2011, 21/03/2011.

17 Uma coleção didática engloba os livros didáticos de um determinado nível escolar lançados pela mesma editora. Por exemplo, uma coleção didática para os anos finais do ensino fundamental engloba quatro livros didáticos, um para cada ano $\left(6^{\circ}, 7^{\circ}, 8^{\circ}\right.$ e $\left.9^{\circ}\right)$. 
deve organizar-se de forma a garantir ao aluno: [...] o desenvolvimento de atitudes, competências e habilidades envolvidas na compreensão da variação linguística e no convívio democrático com a diversidade dialetal, de forma a evitar o preconceito e valorizar as diferentes possibilidades de expressão linguística ${ }^{18}$.

Frente às orientaçôes quanto ao tratamento a ser atribuído à diversidade linguística no ensino de LP, nas quais se enfatiza a importância de fazer com que o aprendiz saiba reconhecer variantes linguísticas, bem como os fatores sócio-histórico-culturais que estão associados a elas e, principalmente, desenvolva tolerância e respeito à língua apresentada por outro falante, decidimos, neste trabalho, observar como as variedades linguísticas estão presentes em LDP e compreender em que medida a forma como as variedades estão sendo tratadas está em consonância com as orientaçôes acima mencionadas.

\section{Corpus da pesquisa}

Para seleção do LDP a ser analisado, buscamos, no Guia de livros didáticos, mencionado acima, informações sobre as coleções didáticas aprovadas, via PNLD 2011, para posterior escolha pelos professores nas escolas de educação básica. A partir de uma comparação que realizamos em trabalho anterior ${ }^{19}$ entre os quadros esquemáticos ${ }^{20}$ referentes a cada uma das 16 coleçóes aprovadas, percebemos que a oralidade, foco da pesquisa de doutorado da autora ${ }^{21}$, só é mencionada como ponto forte, na avaliação da Coleção - Projeto Radix,

18 Ibid., p. 20

19 WINCH, Paula. Gaida. "Leitura, produção textual, oralidade e conhecimentos linguísticos: possíveis avanços entre PCN-EF e PNLD 2011”. In: SEMINÁRIO SOBRE INTERAÇÃO UNIVERSIDADE/ESCOLA, 2; SEMINÁRIO SOBRE IMPACTOS DE POLÍTICAS EDUCACIONAIS NAS REDES ESCOLARES, 2, 2011, Santa Maria. Anais... Santa Maria, Universidade Federal de Santa Maria, 2011. CD-ROM.

20 Os quadros esquemáticos são compostos por cinco itens: pontos fortes; pontos fracos; destaque; adequação ao tempo escolar; manual do professor.

21 A referida pesquisa tem como título "Livro didático de língua portuguesa: caráter e concepção de oralidade subjacentes”, e está sendo desenvolvida no Programa de Pós-Graduação em Letras - PPGL/UFSM), sob orientação de profa. dra. Graziela Lucci de Angelo. 
de Ernani Terra e Floriana Toscano Cavallete ${ }^{22}$. Assim, selecionamos, para constituir nosso corpus de pesquisa, um volume dessa coleção destinado ao ensino de LP para o $8^{\circ}$ ano do ensino fundamental.

\section{Projeto radix - língua portuguesa $-8^{\circ}$ ano do ensino fundamental}

O LDP, escolhido para análise, está organizado em oito módulos, sendo que os módulos ímpares são constituídos por dois capítulos e os pares, por um capítulo, perfazendo um total de 12 capítulos.

Inicialmente, voltamos nossa atenção para o reconhecimento dos exercícios de cunho oral presentes no material. Entre os exercícios dessa natureza, encontramos dois que demonstram explorar a diversidade linguística. Observamos que os demais exercícios que compunham os capítulos, nos quais os dois exercícios estavam inseridos, também faziam referência à diversidade linguística. Assim, optamos por analisar os dois capítulos na íntegra e não somente os dois exercícios de cunho oral.

Dessa forma, centramos nosso olhar no capítulo 5, intitulado "Estrangeiros entre nós", e no capítulo 6, intitulado "Uma nova pátria”. Antes de iniciarmos a análise dos capítulos em questão, apresentamos uma breve descrição dos mesmos. Trata-se de capítulos compostos por 16 páginas, divididos a partir de seçôes, as quais são apresentadas na ordem a seguir: 1) "Hora do texto"; 2) "Expressão oral"; 3) "Expressão escrita"; 4) "Estudo do vocabulário"; 5) "Gramática no texto"; 6) "Para além do texto"; 7) "Hora do texto"; 8) "Expressão escrita"; 9) "A linguagem dos textos"; e, 10) "Produzindo textos". Ressaltamos que, antes da primeira seçâo, há uma atividade introdutória que não está inserida em nenhuma seção e também que a seção "Expressão escrita" engloba questôes de interpretação e não de produção textual como se poderia pensar.

\section{CAPÍTULO 5: “estrangeiros entre nós”}

Para introduzir o tema deste capítulo, há um pequeno texto que trata da questão da migração de brasileiros para o exterior e algumas questóes rela-

22 TERRA, Ernani; CAVAllete, Floriana Toscano. Projeto Radix: português. $8^{\circ}$ ano. São Paulo: Scipione, 2009. Manual do Professor. (Coleção Projeto Radix). 
cionadas a fatores que estariam associados a essa migração. Após, segue com a crônica intitulada "Sofia", de Luis Vilela. A personagem Sofia, uma senhora, apresenta uma forma de falar diferente da habitual na localidade em que reside. Essa fala diferenciada torna-se um elemento de riso entre os moradores da localidade. Em certo momento, diante da bondade com que ela tratava a todos, eles parecem arrepender-se dos risos e decidem parar, mas não conseguem.

$\mathrm{Na}$ seção "Expressão oral", é ressaltada a questão de o personagem falar português, o que torna possível a sua comunicação na localidade em que reside, mas apresenta uma forma de falar diferente devido a seu sotaque. Pede-se, como exercício, para os alunos observarem se há pessoas ao seu redor, no espaço extraescolar, que apresente sotaque diferente.

Na seção "Expressão escrita”, há questões de interpretação que induzem a pensar que a língua falada de modo diferente por Sofia está relacionada ao fato de ela pertencer/ter pertencido a outra nação. Percebemos aqui a língua como elemento identificador de pertencimento ou não de um indivíduo a uma determinada nação.

No "Estudo do vocabulário", encontramos um espaço destinado ao tratamento de uma variedade mais coloquial da língua, a partir da exposição de frases, as quais contêm expressóes bastante coloquiais e que, provavelmente, sejam comuns em espaços geográficos distintos. É questionado o significado dessas expressões.

Na seção "Gramática no texto", tem-se novamente a exploração do significado de expressôes pertencentes a uma variedade mais coloquial da língua.

As três seçôes - "Para além do texto", "Hora do texto" e "Expressão escrita" - apresentam um caráter bastante informativo, visto trazerem orientaçóes para pesquisa sobre o povo árabe, suposta origem da personagem Sofia, e informaçóes sobre a imigração dos árabes no Brasil e suas influências sobre o nosso meio social.

$\mathrm{Na}$ última seção "Produzindo texto", solicita-se que o aluno crie uma narrativa, na qual a personagem central é uma criança. Após elaborados os textos, há troca das composiçóes entre os alunos, para que esses emitam a opiniấo deles. Um dos itens para avaliação dos textos do colega é verificar "se a linguagem utilizada pelos personagens está adequada para a faixa etária deles [dos personagens, no caso, criança]". ${ }^{23}$

${ }^{23}$ TERRA, Ernani; CAVALLETE, Floriana Toscano. Projeto Radix: português. $8^{\circ}$ ano. São Paulo: Scipione, 2009. Manual do Professor. (Coleçáo Projeto Radix), p. 95. 
Essa atividade permite ao aluno perceber que há diferença na língua utilizada também em função da faixa etária do falante. Ressaltamos que a preocupação não reside em verificar se a língua utilizada está correta ou não, tendo a norma culta como parâmetro. Orienta-se aos alunos que se preocupem com o fato de a língua estar adequada ou não à situaçáo comunicativa em que o falante se encontra. Nesse caso, o aluno está em uma situação comunicativa, na qual deve desempenhar "papel" de criança e, consequentemente, utilizar língua adequada a essa faixa etária.

Essa preocupação voltada para a adequação ou não da língua representa uma forma de evitar que a língua, não obedecendo às normas do padrão culto, seja vista como erro, desvio, transgressão, diferente do que se tinha, tempos atrás, quando se via a língua como homogênea e tratava-se a diversidade de forma discriminatória.

\section{CAPÍTULO 6: "uma nova pátria"}

O capítulo inicia com uma atividade cujo objetivo é mostrar as diversas etnias que compóem a sociedade brasileira. Na sequência, é apresentado o conto "Lisetta", de Antonio de Alcântara Machado, no qual uma das personagens - Dona Mariana, mãe de Lisetta - fala português com sotaque italiano e também utiliza algumas expressóes em italiano no diálogo que estabelece com a filha.

Na seção seguinte ao conto, "Expressão oral", pede-se a realização da leitura expressiva do conto, sendo que o aluno é convidado a observar o modo como se deve reproduzir as onomatopeias, o choro de Lisetta e a língua utilizada por Dona Mariana, com traços e expressóes da língua italiana.

$\mathrm{Na}$ seção "Expressão escrita", as questôes estão voltadas para as caraterísticas do texto narrativo e para a interpretação. Como curiosidade, são apresentados os poemas "Migna Terra" e "Versignos", de Juó Bananère, nos quais "há mistura de palavras portuguesas e italianas, na tentativa de reproduzir a maneira de falar dos imigrantes italianos que vieram para o Brasil" 24 .

24 TERRA, Ernani; CAVAllete, Floriana Toscano. Projeto Radix: português. $8^{\circ}$ ano. São Paulo: Scipione, 2009. Manual do Professor. (Coleção Projeto Radix), p. 101. 
A seção "Para além do texto" apresenta caráter informativo, pois sugere que se realize uma pesquisa sobre a imigração italiana no Brasil, a partir de algumas questôes orientadoras. Curiosamente, no texto apresentado na sequência do capítulo - na segunda seção "Hora do texto" - , há respostas para as questões.

Nas seções seguintes - "Expressão escrita", "A linguagem dos textos" e "Produzindo textos" - não encontramos exercícios que envolvam diversidade linguística, estando esses mais voltados a orientar a produção de um texto narrativo.

\section{Apontamentos quanto ao tratamento atribuído à diversidade linguística}

Em ambos os capítulos analisados, temos a diversidade linguística representada pelo sotaque de uma das personagens. Observamos que na língua utilizada pela personagem principal do texto do capítulo 5, Sofia, as diferenças em relação à LP são em nível de morfologia e de sintaxe, por exemplo, nas frases: "Eu vai contar bra seu pai"; "Moleques! Sembregonhas!". Temos o uso de "bra" no lugar de "para o", a conjugação do verbo em terceira pessoa do singular "vai" quando o pronome remete à primeira pessoa do singular "eu" e à mudança de letras em palavras, como troca de "ver" por "bre".

Enquanto nas falas da personagem Dona Mariana - do capítulo 6 - não percebemos mudanças nas palavras que compóem o campo lexical da LP; por exemplo, "Scusi, Senhora. Desculpe, por favor. A senhora sabe, essas crianças são muito levadas. Scusi. Desculpe.” Nas falas dessa personagem, notamos sim o uso de expressões em italiano junto a léxicos em LP, como no exemplo acima, ou somente o uso de expressôes em italiano, tais como: "Stai zitta"; "Stai ferma a ti amazzo, parola d'onore", cuja compreensão só é possível a partir de conhecimentos da língua italiana.

Permite-se, assim, ao aluno observar que a influência advinda da origem étnica do falante pode se manifestar de forma variada na língua utilizada por ele, a partir de alteraçóes morfológicas em léxicos da LP, da inclusão de expressóes estrangeiras junto a expressóes em LP, ou ainda, do uso de expressóes estrangeiras no lugar de expressóes em LP.

Notamos, nesses dois capítulos, que há certa limitação nas atividades apresentadas no livro em análise, por se tratar a diversidade linguística, pre- 
sente na sociedade brasileira, a partir de apenas dois fatores que podem ser tomados como causas para essa diversidade - a origem étnica e a faixa etária do falante. Podemos compreender, em parte, a referida limitação pelo fato de esse livro, assim como os demais aprovados no âmbito do PNLD, ser pensado e elaborado para uso nacional - o que não lhe possibilita tratar das diferenças regionais, dos dialetos de determinadas regióes pela impossibilidade de contemplar todos os dialetos ou regionalismos e, assim, tendo que dar prioridade a alguns e desprezar outros.

Também não são trabalhadas, no livro, variaçóes linguísticas provocadas por outros fatores, tais como: sexo, profissão, classe social, região geográfica, entre outros.

Consideramos muito pertinente o fato de que, nestes dois capítulos, engloba-se a questão cultural das diferentes etnias - árabe e italiana -, sua influência sobre nossa cultura, a herança desses povos para a sociedade atual e suas questóes históricas, incluindo seu processo migratório - motivos, datas, sua economia, enfim, parte de sua história vivenciada no Brasil.

De um modo geral, a diversidade linguística é tratada a partir de atividades em que aluno tem de identificar a variante linguística, os fragmentos em que ela é perceptível e buscar reproduzi-la. Acreditamos que poderia ser dada maior ênfase à questão de o falar diferente não poder ser visto como uma razão para discriminaçáo social - um aspecto bastante mencionado em documentos legais, mas pouco abordado nos capítulos analisados do LDP.

\title{
LINGUISTIC DIVERSITY AT PORTUGUESE TEXTBOOK: SOME CONSIDERATIONS
}

\author{
ABSTRACT \\ It is analyzed how linguistic diversity is dealt with in a \\ Portuguese textbook, where two chapters are designated \\ to it. In these, it is pointed out that speaker ethnic origin \\ can be manifested differently by: morphological changes; \\ use of foreign expressions; accent in oral language. In \\ synthesis, the linguistic diversity is dealt with through \\ activities of identification and reproduction of linguistic \\ varieties to be carried out by the students.
}


KEYWORDS: linguistic diversity; teaching; Portuguese Language.

Recebido em: 25/02/2013

Aprovado em: 12/08/2013 